\title{
Epidemiology of infectious complications in endo-arterial interventional radiology in France: Feasibility of the nationwide hospital discharge database (PMSI), 2010 - 2013.
}

\author{
Kaoutar Aid Mellouk ${ }^{1}$, Abdelmajid Soulaymani², and Benoit Misset $^{3}$ \\ 1 : Université des Sciences Ibn Tofail - Kénitra, Maroc, Centre d'études Doctorales, Laboratoire de génétique et Biométrie ; \\ Tél : +33(0)6 621564 24, Fax : +33(0)1 402742 17, E-mail : kaoutarmellouk92@,gmail.com \\ 2 : Université des Sciences Ibn Tofail - Kénitra, Maroc, Centre d'études Doctorales, Laboratoire de génétique et Biométrie ; \\ Tél : +212 (0)661 9781 37, Fax : +212 (0)537 3294 33, E-mail : soulaymani@uit.ac.ma \\ 3: Department of Intensive Care Medicine, University Hospital, Liège, Belgium; \\ Tél : +32 4(0)284 3826, E-mail : benoit.misset@,chuliege.be
}

\begin{abstract}
Introduction : The epidemiology of the Healthcare-Associated Infections (HAI) postEndoArterial Interventional Radiology Procedures (EAIRP) is unknown. The objective is to test the feasibility of the nationwide hospital discharge French database, named, le Programme de Médicalisation des Systèmes d'Information (PMSI) to determine the incidence of IN post- EAIRP. The procedures selected are: Angioplasty, angioplasty with stent, embolization and thrombectomy. Subjects and methods: Denominator: patients with at least one stay including the code "trans/arterial route" of the French Common Classification of Medical Acts. Numerator: cases of HAls according to the International Classification of Diseases in its French version, Tenth Revision. The study was approved by the French National Commission for Data Protection and Liberties. Results: 460,461 patients included in 692 centers from 2010 to 2013. $9,227(2.01 \%)$ infections within 3 months of an EAIRP. Mortality $2.79 \%$ without HAI, versus $9.77 \%$ with $\mathrm{HAl}(\mathrm{P}<0.001)$. Conclusion: Measuring the incidence of HAI secondary to an EAIRP with the PMSI is feasible. The HAI appears to be associated with excess mortality. The causal link between $\mathrm{HAl}$ and death deserves to be deepened. Comparisons with databases from other countries are necessary.

Keywords (words) :

Interventional Radiology, PMSI, Healthcare-Associated Infections.
\end{abstract}

\section{Introduction}

Annually worldwide, around 7 million patients undergo EAIRP and these percutaneous Interventional procedures are expected to escalate further in coming years[1].

The EAIRP encompasses a range of procedures and techniques wide. It includes, diagnostic angiography, placement of an arterial closure device, angioplasty, angioplasty with a stent, thrombolysis, chemoembolization and embolization, placement in place of a terminal graft, intrahepatic transjugular portosystemic shunt and uterine artery embolization [2].

EAIRP, as a surgical activity, is confronted at a real risk of infection, which varies according the use or not of an established medical device and whether to the general state of patient[3].

Today, our insights is limited about the infectious complications post-EAIRP[4][5][6]. The Key for prevention and the effective fight against of healthcareassociated infections (HAIs), is now surveillance of these HAIs [7]. however, monitoring is often laborintensive and time-consuming [8], hence rare the studies have estimated the prevalence of HAIs post-EAIRP.
Some studies have estimated the risk as $4.9 \%$ for all arterial and venous angioplasties and $0.64 \%$ for coronary angioplasty [9][10]. Others have reported the occurrence of prosthetic vascular graft infection with a cumulative incidence varying from $0 \%$ to $3.1 \%$ [13] and $0.5 \%$ to $5 \%$ [11][12]. Data were associated with a low level of evidence [15] and heterogeneous [14]. The majority studies provided information on a microbial ecology cannot be extrapolated to another center [16] and were monocentric [17].

The objective of this study is to test the feasibility of the nationwide hospital discharge French database (PMSI) to determine the incidence of HealthcareAssociated Infections (HAI) post- EAIRP.

\section{METHODS AND ANALYSIS}

The PMSI is an exhaustive national database of the hospitalizations. In France, PMSI is in mandatory use [18], per year it generates 25 million stays [19]. Each hospital stay is subject to a standardized discharge summary. The data collected has been anonymized and chained since 2001. A unique number allowing the stays of the same patient to be linked, without having to 
discover their identity. The stay database of the EAIRP, containing the FCCAM codes of the procedures selected (Angioplasty, angioplasty with stent, embolization and thrombectomy) [5] was extracted from the 2009-2014 PMSI database that covers all public and private hospitals in France as well as those in the French Territories[20][21]. Thereafter, we proceeded to the selection the of abstracts of which one or more diagnostic codes of the ICD-10 were suggestive of HAI (Table 1) according to the coding clinicians (surgeons, infectiologists, cardiologists, radiologists, neuroradiologists, gastroenterologists, etc...).

For identification of keywords of HAI post- EAIRP and in harmony with other studies [8][5], we selected keywords such as 'wound', 'abscess', 'drainage', 'sepsis', 'infection of the point of puncture', 'bacteremia', 'infection of surgical site', 'septic shock', 'infection acquired at the hospital and 'nosocomial infection'. The bacterial and fungus infections will be considered. thereafter we identified two lists of diagnostic codes of infection from ICD-10. A list that will include the codes of inflammation embolic of mechanic lesions which may be imputed to infection. We named this list "unspecificcode". Another list who will include either anatomical location of infection or the pathogen agent. We called this list 'specific-code'.

we will retain the cases of infection based on the presence of diagnosis codes in the ICD-10 (unspecific code, specific code), which we will associate with to other surgical acts of the FCCMA qualified of the repairer of the initial act. The surgical repair act will be named specific act of HAI post-EAIRP (Table 1).

Table 1 : Different codes retained for the Denominator identification.

\begin{tabular}{|c|c|c|}
\hline \multicolumn{3}{|r|}{ Numerator's codes } \\
\hline Acts of FCCMA & & Diagnosis codes of the ICD -10 \\
\hline $\begin{array}{l}\text { Specific act: for repair } \\
\text { of the initial EAIRP acts }\end{array}$ & Unspecific code & Specific code \\
\hline $\begin{array}{l}\text { DCJA010, ECFA006, } \\
\text { DCJA021, QZJA001, } \\
\text { DCJA032, EDFA009, } \\
\text { DCJA002, QBFA014, } \\
\text { ZZQL011, ZZQL015, } \\
\text { DCJA025, DCJA028, } \\
\text { EDFA010, QZJA023, } \\
\text { DCJA005, DCJA018, } \\
\text { ECMA001, DCJA014, } \\
\text { EDKA002, DCJA024, } \\
\text { QZJA002, DCJA023, } \\
\text { DCJA009, DCJA003, } \\
\text { DCJA031, DCJA012, } \\
\text { DCJA013, QZJA017, } \\
\text { DCJA007, DCJA033, } \\
\text { DCJA030, DCJA019, } \\
\text { QZJA013, DCJA020, } \\
\text { DCJA011, DCJA022, } \\
\text { DCJA026, QZJA012, } \\
\text { DCJA008, EDSA003, } \\
\text { QZQA001, EDSA002, } \\
\text { DCJA015, EDPA001, } \\
\text { DCJA017, DCJA002, } \\
\text { QZJA015, EDKA003, } \\
\text { DCJA006, DCJA027, } \\
\text { DCJA016, QZJA016, } \\
\text { DCJA029, EZSA003 } \\
\text { DCJA004, DCJA001, }\end{array}$ & $\begin{array}{l}\text { R509, R650, } \\
\text { R508, R651, } \\
\text { R502, I748, } \\
\text { I740, I742, } \\
\text { I741, I770, } \\
\text { I743, I248, } \\
\text { I259, I745, } \\
\text { I749, I744, } \\
\text { I249, }\end{array}$ & 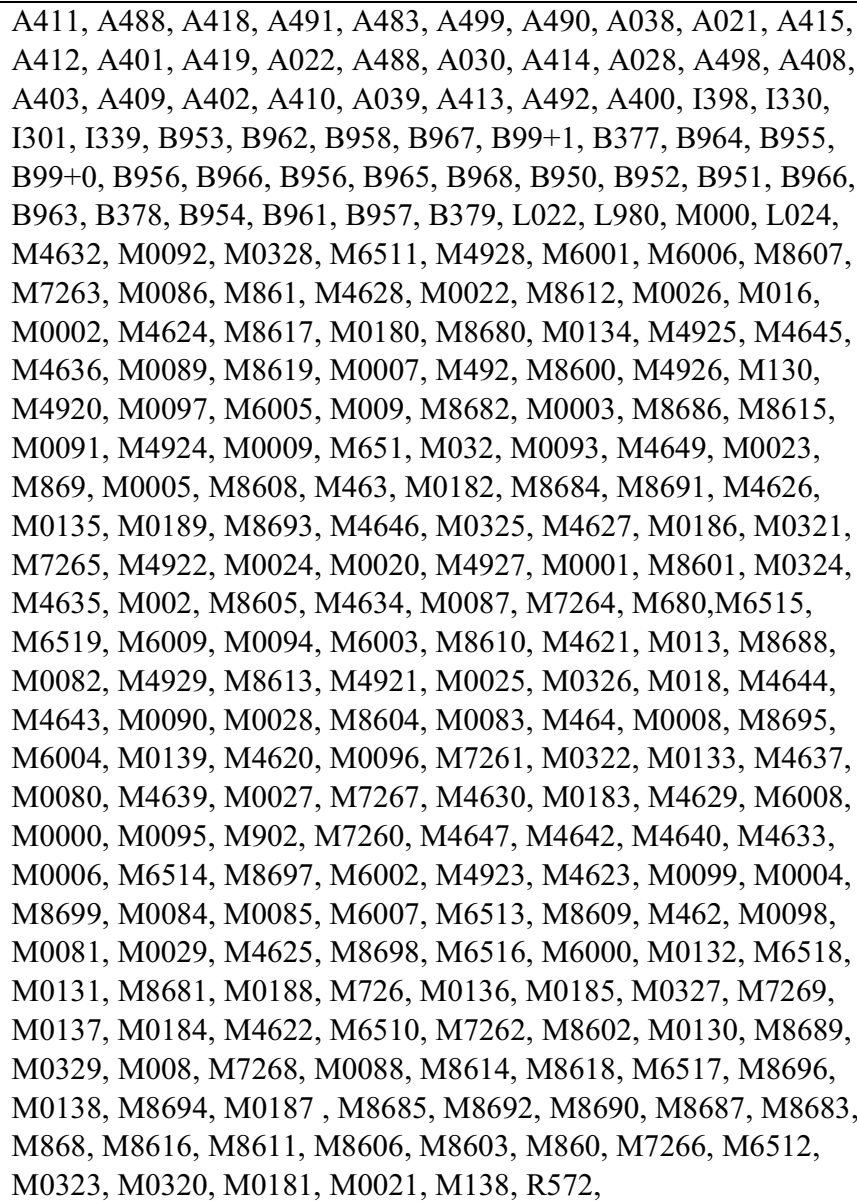 \\
\hline
\end{tabular}

We then defined 2 diagnostic situations according to the codes and their position in the coding: HAIs post EAIRP certain or probable (Table 2). Thereafter patients were identified using algorithm developed during our previous publication « MOEVA study » specifically designed to identify EAIRP in the French national hospital database [5]. 
For each stay, were analyzed: the type and location of the hospital, the admission and discharge mode, the provenance and destination, length of stay, place of residence (geographic codes), the surgical acts performed that participate in the classification and inhospital mortality. From the « stays» base, was extracted the « patients» database, thanks to use the chaining. Only stays falling within the definition of cases and with correct chaining could be used[5]. The annual incidence of HAIs post EAIRP was calculated generally as well as by age, gender and region. The denominator is all the

Table 2 : Case definition for the numerator identification target stays. For the numerator, each patient was counted as a « new case», the rehospitalizations during the period with ICD-10 code defined infection being considered as a relapse

and /or infectious complications of the EAIRP act. For each patient, were analyzed the socio-demographic data, the numbers and duration of stays and the coded microorganism.

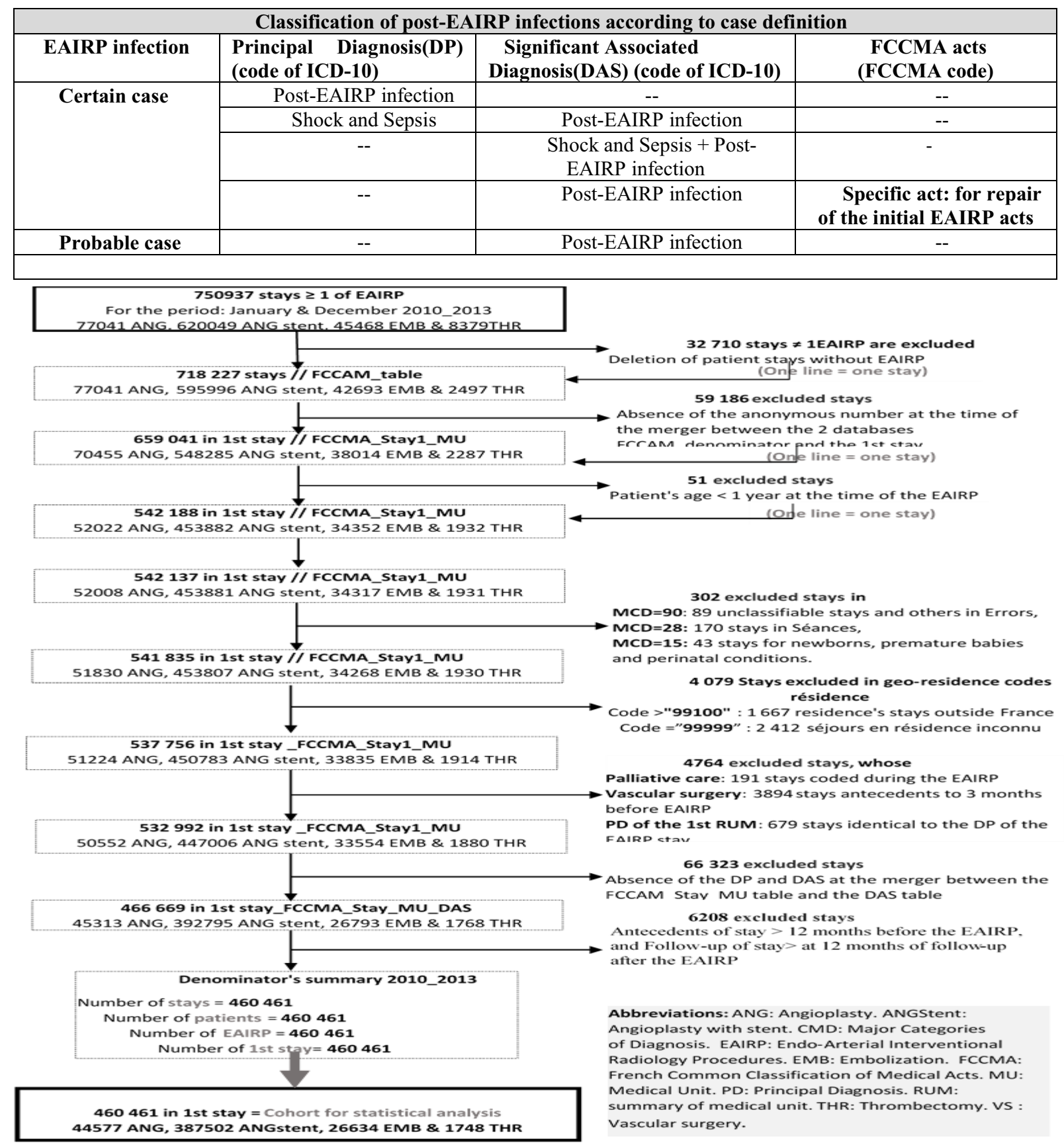




\section{Results}

\subsection{Stay}

The initial base included 750,937 stays spread over the 4 years: only 460,461 stays fell within the cases definition. The acts of EAIRP are divided between 44577 Angioplasty (ANG), 387502 Angioplasty with stent (ANGstent), 26634 Embolization (EMB) et 1748 Thrombectomy (THR). A study flowchart who summarizes the population selection process is illustrated in (Figure1) descriptive analyses for sociodemographic, clinical, and hospital data were presented as frequencies and percentages (Table 3 ).

In total 692 health care institution in France were included between January 2010 and December 2013. The geographical distribution of the hospitals attended was comparable to that of the place of residence. The greatest number of stays was recorded in Ile-de-France (13.64\%) and Rhône Alpes (10.30\%). The stays in public hospitals $348(50.29 \%)$ slightly exceed those made in the private sector $344(49.71 \%)$.

The origin of the entries in $90.74 \%$ of the patients was admitted directly from their home. In $18.74 \%$, the EAIRP procedure was unscheduled. The average length of stay was 6.5 days, with a median length of 4 days. $47.56 \%$ of the cases involved a short hospital stay of less than 3 days, $4.80 \%$ of which involved a stay in intensive care unit and $30,645(13.45 \%)$ patients were admitted to a surgical department. $88.10 \%$ of cases received a diagnostic radiology procedure. Regarding the mode of discharge, the majority of patients 378996 (82.44\%) went home, $12852(2.79 \%)$ stays recorded a death 3 months after the EAIRP procedure and 13765 (2.99\%) deaths 12 months later.

Table 3 : Demographic and Clinical Characteristics of the Study Population $(n=460461)$

\begin{tabular}{|c|c|c|c|}
\hline \multicolumn{3}{|c|}{$\begin{array}{ll}\text { Characteristics } \\
\end{array}$} & n(\%) \\
\hline \multirow{3}{*}{ 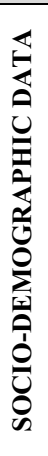 } & $\begin{array}{c}\text { Age at EAIRP } \\
\text { act }\end{array}$ & $\begin{array}{l}<=30 \\
{[30-40[} \\
{[40-50[} \\
{[50-60[} \\
{[60-70[} \\
{[70-80[} \\
{[80-90[} \\
>90\end{array}$ & $\begin{array}{l}4977(1.08) \\
10981(2.39) \\
40353(8.77) \\
88127(19.15) \\
113209(24.60) \\
118089(25.66) \\
77810(16.91) \\
6674(1.45)\end{array}$ \\
\hline & Sex & $\begin{array}{l}\text { Male } \\
\text { Female } \\
\end{array}$ & $\begin{array}{l}327095(71.04) \\
133366(28.96)\end{array}$ \\
\hline & $\begin{array}{l}\text { Year of the } \\
\text { study }\end{array}$ & $\begin{array}{l}2010 \\
2011 \\
2012 \\
2013\end{array}$ & $\begin{array}{l}135598(29.45) \\
119486(25.95) \\
123132(26.74) \\
82245(17.86)\end{array}$ \\
\hline \multirow{3}{*}{ 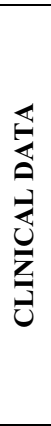 } & Type of EAIRP & $\begin{array}{l}\text { Angioplasty } \\
\text { Angioplasty with } \\
\text { stent } \\
\text { Embolization } \\
\text { Thrombectomy }\end{array}$ & $\begin{array}{l}44577(9.68) \\
387502(84.16) \\
26634(5.78) \\
1748(0.38)\end{array}$ \\
\hline & Comorbidity & $\begin{array}{l}\text { No } \\
\text { Yes }\end{array}$ & $\begin{array}{l}65954(14.32) \\
394507(85.68)\end{array}$ \\
\hline & $\begin{array}{l}\text { Number of } \\
\text { comorbidities } \\
\text { per patient }\end{array}$ & $\begin{array}{l}0 \\
1 \\
2 \\
3 \\
4 \\
>5 \\
\end{array}$ & $\begin{array}{l}65954(14.32) \\
157007(34.10) \\
134503(29.21) \\
63237(13.73) \\
25133(5.46) \\
14627(3.18) \\
\end{array}$ \\
\hline \multirow{4}{*}{ 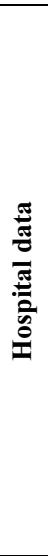 } & Input mode & $\begin{array}{l}\text { Temporary } \\
\text { transfer } \\
\text { Mutation } \\
\text { final transfer } \\
\text { Domicile From } \\
\text { home }\end{array}$ & $\begin{array}{l}587(0.13) \\
675(0.15) \\
41318(8.99) \\
417145(90.74)\end{array}$ \\
\hline & Hospital type & $\begin{array}{l}\text { Public Hospital } \\
\text { Privat Hospital }\end{array}$ & $\begin{array}{l}348(50.29) \\
344(49.71)\end{array}$ \\
\hline & $\begin{array}{c}\text { hospitalization } \\
\text { service after } \\
\text { EAIRP act }\end{array}$ & $\begin{array}{l}\text { Acute care unit } \\
\text { Usi usc } \\
\text { Palliative care } \\
\text { Surgery } \\
\text { Non surgery }\end{array}$ & $\begin{array}{l}10949(4.80) \\
145349(63.77) \\
102(0.04) \\
30645(13.45) \\
40869(17,94 \%)\end{array}$ \\
\hline & $\begin{array}{l}\text { The length of } \\
\text { time of stay of } \\
\text { the EAIRP act }\end{array}$ & $\begin{array}{l}0 \\
{[0-3[} \\
{[3-7]} \\
>7 \\
\end{array}$ & $\begin{array}{l}2807(0.61) \\
218173(47.56) \\
136084(29.66) \\
101684(22.17)\end{array}$ \\
\hline
\end{tabular}

Figure 1 : Flowchart of population selection for statistical analysis - MOEVA cohort

\subsection{Patients}

In the initial database, only $61.31 \%$ of stays could be chained. After submitting the correctly chained stays to the case definition, the number of patients hospitalized for EAIRP procedures was 460461, respectively 135598 in 2010 and 82245 in 2013. 95.61\% of patients were hospitalized only once during the 3 months of follow-up after the procedure, $9.23 \%$ of patients had at most 2 hospitalizations during the year.

The sex ratio was 2.45 , the average age is 67 years (median 68 years, extremes 2 to 100 years). Analysis by age group showed that those under 30 years of age represented $1.08 \%$ of patients with a difference in distribution by sex. In the overall population, there was a clear male predominance of the pathology $(71.04 \%$ with $\mathrm{p}<0.0001)$. There were $12852(2.79 \%)$ deaths in the general population, this rate increases significantly in patients who developed HAIs to reach a $9.77 \%$ incidence of death. The average length of stay for deaths was 14 days, with a median length of 7 days.
The overall incidence of HAIs, 3 months after the interventional procedure was 9227 cases $(2.01 \%), 1.83 \%$ in men and $2.76 \%$ in women. The incidence also varies with age, going from $1.60 \%$ in the [30-40]-year-old age group to $6.05 \%$ in the over-90 age group (Figure 2). The share of HAIs in patients under 30 years of age is $3.84 \%$ are mostly at the origin of a genetic malformation.

Among the selected acts of the study, Angioplasty with stenting represents an $1.44 \%$ incidence of infection. Embolization is associated with a high incidence $4.64 \%(p<0.0001)$ of HAIs. The analysis of the incidence evolution during the 4 years of the study reveals that the infection increases according to the years. $1.76 \%$ in 2010 against $2.28 \%$ in 2013 . This result can be explained by the medical progress and the interesting and increasingly invasive possibilities that EAIRP can offer. 
In $23.70 \%$ of cases, no microorganism was indicated. $99.30 \%$ of patients had no bacteremia history at the time of the EAIRP. Among the $76.30 \%$ of microbiologically documented cases, E. Coli is the most frequent with

A comorbidity was coded in $85.68 \%$ of the population. $64.96 \%$ of patients had cardiovascular pathologies, $47.53 \%$ of hypertension, $11.90 \%$ of diabetes and $6.02 \%$ of renal failure. $34.10 \%$ of patients had a single comorbidity and $29.21 \%$ had 2 . The analysis also shows that the HAIs incidence increases with the presence and multiplicity of comorbidities. Thus the HAIs incidence is $1.75 \%(\mathrm{p}<0.0001)$ in patients with 2 comorbidities. The latter increases significantly until it reaches $10.26 \%$ in patients with more than 5 comorbidities (3.18\% of the population). Finally, among the risk factors, smoking is present in $15.08 \%$ of cases.

Figure 2 : Incidence of HAIs of EAIRP by age, PMSI 2010-2013

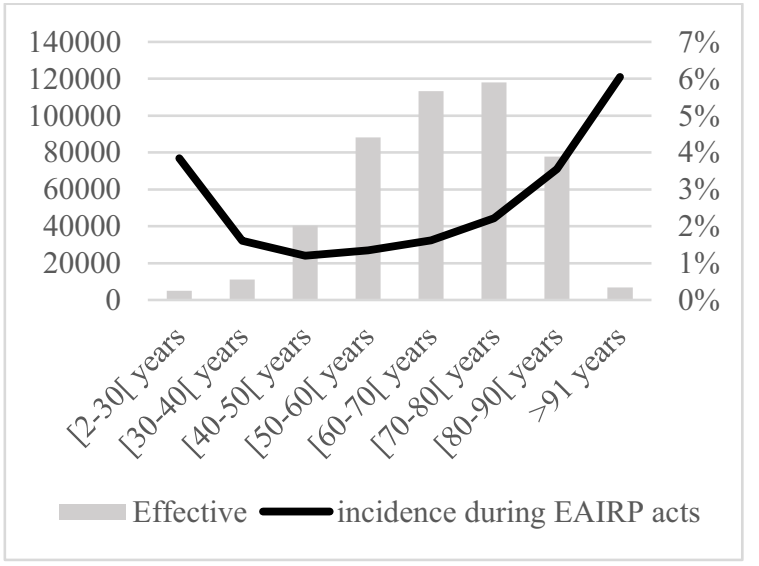

\section{Discussion}

The PMSI is an economic and budgetary program [22], whose use in epidemiology has long been limited by the difficulty of stays chaining of a same and single patient. Since the creation of a patient unique anonymous identifier, it is possible to link the stays to the patient and to follow his care path [23]. Therefore, we used the PMSI to estimate the EAIRP incidence, minimally invasive intervention usually diagnosed and treated in a hospital setting and for which there are no epidemiological studies either nor to a national or nor international scale.

The incidence of HAIs measured here in 2010-2013 is draw near to rare estimates from Occidentals countries[22][11][23]. The prevalence of AHI varies mainly according to patient characteristics or exposure to certain risk factors: all the more higher than the patients were elderly, of male gender, with one or more severe diseases. These identical findings were observed in a national epidemiological survey of the prevalence of nosocomial surgical site infections, France, June 2006[24].

This study highlights the importance of HAIs surveillance, in terms of field (age, comorbidities...), of care $(13.45 \%$ of surgical stays, $4.80 \%$ transition to intensive care unit) and the evolution (2.79\% of deaths).
23.91\%, followed by BMR with 21.21\%, Staphylococcus was coded in $16.90 \%$ of cases and Staphylococcus aureus in $3.57 \%$ (Table 4).

However, the description of the pathology through the PMSI is imperfect, given the limitations of the coding.

The coding of stays is performed by various actors. The codes used and their position in the summary vary depending on the coder. Given the complexity of EAIRP coding and its complications, we compared our results with those published in a report by the High Authority on Healthcare in 2014[25]. The number of interventional radiology procedures in 2010 is compatible with that which we extracted from the PMSI database, which validates the choice of our CCAM codes for the denominator. 
Table 4 : Distribution of coded microorganisms in EAIRP, France, 2010-2013.

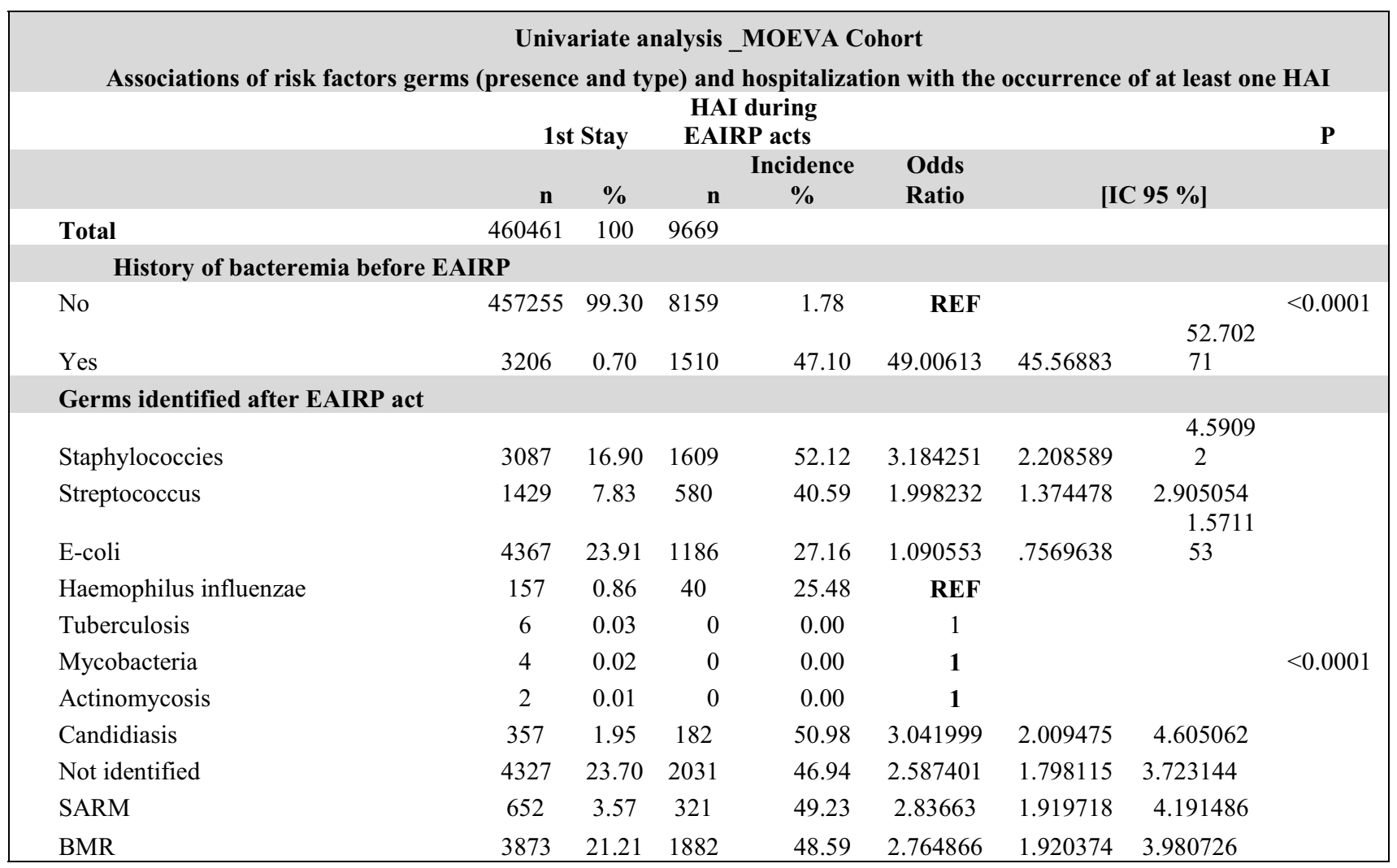

Chaining was still imperfect $(38.69 \%$ non-chained stays). The prevalence of EAIRP acts by year is not coherent. We note a decrease in the number of acts recorded in 2013 despite the fact that the chaining is currently of much better quality. Likewise, increased reinforced attention to the quality coding has become necessary since the reform of Pricing per activity (T2A), and the controls put in place by health insurance, since then.

The PMSI provides poor information on microbiological etiology: difficulty in the germ isolation (30 to $40 \%$ of cases in the literature)[25] or faulty coding because without financial consequences. Similarly, comorbidities are difficult to exploit from the PMSI. Certain pathologies can be coded more easily when they overvalue the stay, such as diabetes.

Although the algorithm used to identify patients requiring an EAIRP act has been validated internally, it has not yet received external validation. The algorithm could be improved in the future, which would increase HAI identification rates in hospitalized EAIRP patients.

\section{References}

1 A.Manzil, S.Vala, Int $\mathrm{J}$ Res Med Sci. Percutaneous vascular closure device of the femoral access site after coronary interventions for acute coronary syndrome -immediate and short term follow-up. 5, 778-81 (2017).
In conclusion, the France EAIRP incidence is estimated at $2.01 \%$, number that is coherent with the only available estimates [22][11][23]. The epidemiological characteristics are superimposed on the data in the literature and some reports of the competent authorities in France. The PMSI's use, despite its methodological limitations and possible biases, made it possible to estimate the weight of this pathology at the national level.

The results observed in this study require adequate validation. Such as, further studies focused on the etiology, the risk factors (terrain, part of iatrogeny in the occurrence of the infection)

In addition to lifting the anonymity on certain medical records to verify the chosen case definition, would certainly be useful to complete the basic data provided by the PMSI.

We thank Dr Maiga Oumou for his helpful comments and for proof-reading the manuscript.

Société Française de Radiologie, SFR. la Radiologie Interventionnelle en France. 1-27 (2011).

3 T.G. Walker, S.P. Kalva, K. Yeddula, et al, J Vasc Interv Radiol. Clinical practice guidelines 
for endovascular abdominal aortic aneurysm repair: Written by the standards of practice committee for the society of interventional radiology and endorsed by the cardiovascular and interventional radiological society of Europe and the Canadian interventional radiology association. 21, 1632-55 (2010).

4 K. Mellouk Aid, H. Tchala Vignon Zomahoun, A. Soulaymani, et al, Syst Rev. Mortality and infectious complications of therapeutic endovascular interventional radiology: $A$ systematic and meta-analysis protocol. 6, 89 (2017).

5 K. Aid Mellouk, A. Soulaymani, F. Gao, et al, BMJ Open. Infectious complications of endoarterial interventional radiology: Protocol for an observational study of a longitudinal national cohort of patients assessed in the French hospital discharge database (MOEVA study). 9 (2019).

6 F. Camou, L. Legout, J. Caillon, et al, Reanimation. Traitement des infections de prothèse vasculaire. 25, 296-307 (2016).

J.I. Tokars, C. Richards, M. Andrus, et al, Clin Infect Dis. The Changing Face of Surveillance for Health Care--Associated Infections. 39, 1347-52 (2004).

M. Apte, T. Landers, Y. Furuya, et al, Surg Infect. Comparison of Two Computer Algorithms To Identify Surgical Site Infections. 12, 459-64 (2011).

9 S. Malavaud, F. Joffre, J. Auriol, et al, Elsevier Masson. Hygiene recommendations for interventional radiology Abbreviations. 93 (2012).

10 S.L. Meyerson, T. Feldman, T.R. Desai, et al, Vasc Endovascular Surg. Anglographic Access Site Complications in the Era of Arterial Closure Devices. 36 (2002).

11 R.O. Darouiche, N Engl J Med. Treatment of infections associated with surgical implants. 350, 1422-9 (2004).

12 S.F. Fitz Gerald, C. Kelly, H. Humphreys, J Antimicrob Chemother. Diagnosis and treatment of prosthetic aortic graft infections: confusion and inconsistency in the absence of evidence or consensus. 56, 996-9 (2005).

S. Homer Vanniasinkam, Int $\mathrm{J}$ Infect Dis. Surgical site and vascular infections: treatment and prophylaxis. 11, 17-22 (2007).
J.M. Wardlaw, F.M. Chappell, J.J.K Best, et al, Lancet. Non-invasive imaging compared with intra-arterial angiography in the diagnosis of symptomatic carotid stenosis: a meta-analysis. 367, 1503-12 (2006).

Z.J. Eapen, A.J. McBroom, R. Gray, et al, Circ Cardiovasc Qual Outcomes. Priorities for comparative effectiveness reviews in cardiovascular disease. 6, 139-47 (2013).

16 C.A. Holmstedt, T.N. Turan, M.I. Chimowitz, et al, Lancet Neurol. Atherosclerotic intracranial arterial stenosis: risk factors, diagnosis, and treatment. 12, 1106-14 (2013).

P. Otal, J. Auriol, V. Chabbert V, et al, J Radiol. Radiologie interventionnelle et traumatismes thoraco-abdomino-pelviens. 89, 1855-70 (2008).

18 M.K. Cbmdlseds, Bull Off No 2009/5 bis Fasc spécial-ministère la santé des sport. Guide méthodologique de production des informations relatives à l'activité médicale et à sa facturation en médecine, chirurgie, obstétrique et odontologie-- Annexe II de l'arrêté du 20 janvier 2009. 108 (2009).

19 J. Pinaire, J. Rabatel, J. Azé J, et al, SIIM 2015. Recherche et visualisation de trajectoires dans les parcours de soins des patients ayant eu un infarctus du myocarde. (2015).

G. Buisson, Direction de la recherche, des études, de l'évaluation et des statistiques DREES. Redressements du Programme de Médicalisation des Systèmes d'Informations PMSI. 1-28 (2005).

21 M, Goldberg, Haut conseil de la Sante Publique. Les systèmes d'information pour la santé publique. 1-363 (2009).

22 S.L. Meyerson, T. Feldman, T.R. Desai, et al, Vasc Endovascular Surg. Anglographic Access Site Complications in the Era of Arterial Closure Devices. 36:137-44 (2002).

23 S.F. Fitzgerald, C. Kelly, H. Humphreys, J Antimicrob Chemother. Diagnosis and treatment of prosthetic aortic graft infections: confusion and inconsistency in the absence of evidence or consensus. 56:996-9 (2005).

24 RAISIN (Réseau d'alerte d'investigation et de surveillance des infections nosocomiales). Enquête nationale de prévalence des infections nosocomiales. (2006).

25 S. Baron, L. Grammatico Guillon, J.M. Besnier, et al, Rev Epidemiol Sante Publique. Épidémiologie de la spondylodiscite infectieuse en France, 2002-2003. L'apport du programme médical des systèmes d'information (PMSI). 56:38 (2008). 